\title{
Antioxidant and antimalarial properties of Sophora exigua Craib. root extract in Plasmodium berghei-infected mice
}

\author{
Kantarakorn Kaewdana, Prapaporn Chaniad, Pitchanee Jariyapong, Arisara Phuwajaroanpong and \\ Chuchard Punsawad ${ }^{*}$ (D)
}

\begin{abstract}
Background: Sophora exigua Craib. is commonly used in Thailand to reduce fever and increase postpartum breast milk production in women who have hypogalactia. However, there has been no report on the antioxidant and antimalarial properties of this plant. This study aimed to investigate the antioxidant and antimalarial activities of $S$. exigua root extract and to evaluate its acute toxicity in mice to confirm its safety.
\end{abstract}

Methods: The in vitro antioxidant activities were determined using 2,2-diphenyl-1-picrylhydrazyl (DPPH), superoxide radical, and hydroxyl radical scavenging assays. The in vivo antioxidant activities were determined by detecting the malondialdehyde (MDA) content and superoxide dismutase (SOD) activity in the livers of malaria-infected mice. The in vivo antimalarial activity was determined by Peters' 4-day suppressive test in mice infected with Plasmodium berghei ANKA and orally administered S. exigua root aqueous and ethanolic extracts at different doses (200, 400, and $600 \mathrm{mg} / \mathrm{kg}$ body weight). In addition, the acute oral toxicity of the plant extracts was assessed in mice at a dose of $2000 \mathrm{mg} / \mathrm{kg}$ body weight.

Results: The ethanolic extract of S. exigua root exhibited inhibition of DPPH radicals, superoxide anions, and hydroxyl radicals, with half maximal inhibitory concentration $\left(I C_{50}\right)$ values of $24.63 \pm 1.78,129.78 \pm 0.65$, and $30.58 \pm$ $1.19 \mu \mathrm{g} / \mathrm{ml}$, respectively. Similarly, research on the in vivo antioxidant activity indicated that the ethanolic extract of S. exigua root exerted a stronger effect than the aqueous extract. The aqueous extract at doses of 200, 400, and 600 $\mathrm{mg} / \mathrm{kg}$ had stronger antimalarial activity than the ethanolic extract. The aqueous extract at $600 \mathrm{mg} / \mathrm{kg}$ exhibited $60.46 \%$ suppression of parasitemia. Increased levels of aspartate aminotransferase (AST), alanine aminotransferase (ALT), and alkaline phosphatase (ALP) and blood urea nitrogen (BUN) were detected in the mice treated with 2000 $\mathrm{mg} / \mathrm{kg}$ ethanolic extract, which was related to the results of histopathological analysis of liver tissue, showing ballooning degeneration of hepatocytes, diffuse hepatic hemorrhage, and infiltration of inflammatory cells.

Conclusions: This study demonstrated that the ethanolic S. exigua root extract possessed antioxidant properties, and the aqueous extract also had antimalarial activity. Therefore, this plant is an alternative source of new antioxidant and antimalarial agents.

Keywords: Antimalarial activity, Antioxidant activity, Malaria, Sophora exigua

\footnotetext{
* Correspondence: chuchard.pu@wu.ac.th

Department of Medical Sciences, School of Medicine, Walailak University,

Nakhon Si Thammarat 80160, Thailand
}

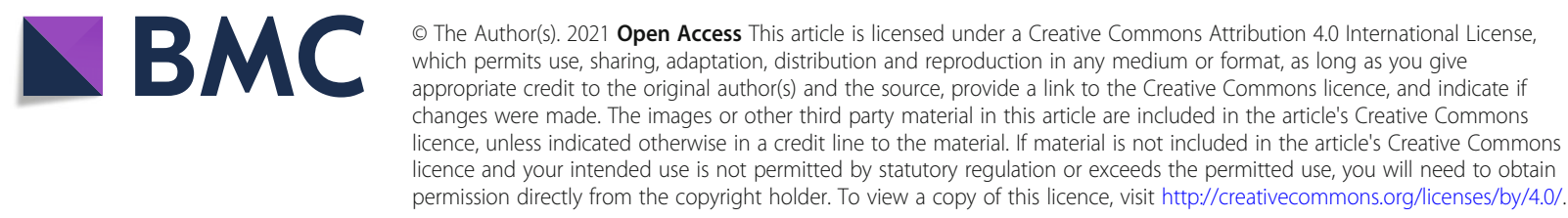




\section{Introduction}

Malaria is a disease caused by Plasmodium parasites, which infect humans and female Anopheles mosquitoes [1]. There are five species of Plasmodium that infect humans, including Plasmodium falciparum (P. falciparum), Plasmodium vivax (P. vivax), Plasmodium ovale (P. ovale), Plasmodium malariae (P. malariae), and Plasmodium knowlesi (P. knowlesi) [1]. The World Malaria Report 2019 estimated that there had been 228 million cases of malaria worldwide, with 405,000 deaths from this disease. Among the deaths, children under 5 years of age constituted 272,000 cases [2]. Recent studies have suggested that the generation of reactive oxygen and nitrogen species (ROS and RNS) associated with oxidative stress plays a crucial role in the development of systemic complications caused by malaria [3]. The effects of ROS in malaria can be both beneficial and pathological, depending on the amount and site of production [4]. High production of free radical species such as nitric oxide that suppress the patient's immune system has been related to malaria complications such as cerebral malaria [5] and acute kidney injury [6] and induces hepatic apoptosis [7].

The use of plant extracts and other natural products for antimalarial activity, antioxidant activity, and prevention of oxidative stress during malaria infection has been of interest for several years [3]. Sophora species have been studied for their antioxidant properties, and S. flavescens [8] and S. japonica [9] have been shown to be good candidates for antioxidants. In addition, (2S)-2' methoxykurarinone, sophoraflavanone G, and leachianone A, isolated from the roots of S. flavescens, exhibited moderate antimalarial activity, with half maximal inhibitory concentration $\left(\mathrm{IC}_{50}\right)$ values of $2.4,2.6$, and $2.1 \mu \mathrm{M}$, respectively [10]. Additionally, the other pharmacological effects of Sophora species include anticancer effects, induction of apoptosis, an effect on hair growth, and antimicrobial and antiviral activities [11].

Sophora exigua Craib., known locally in Thai as Phit sa nat, belongs to the Fabaceae family and is distributed in several parts of Thailand [11]. This plant is an ingredient of Kheaw-hom as traditional Thai remedy, which is commonly used for reducing fever and increasing breast milk production. It has been reported that an extract of S. exigua exhibited antioxidant [12] and antimicrobial activities against Pseudomonas aeruginosa, Staphylococcus epidermidis, and Candida albicans [13]. Additionally, sophoraflavanone G isolated from S. exigua exerts antibacterial effects by decreasing the fluidity of cellular membranes [14]. Based on previous studies, scientific data for $S$. exigua root extract have frequently demonstrated antimicrobial activity, but there is little information on its antioxidant activity and no report on its antimalarial activity. Therefore, this study aimed to investigate the antioxidant and antimalarial activities of $S$. exigua root extract and to evaluate the acute toxicity in mice to confirm the safety of the extract.

\section{Materials and methods \\ Plant material and extraction process}

The roots of S. exigua were obtained from a Thai traditional drug store in Nakhon Si Thammarat Province, Thailand, in 2019. The plant material was identified by Assoc. Prof. Tanomjit Supavita, School of Pharmacy, Walailak University, Thailand. The dried coarse powder of roots $(60 \mathrm{~g})$ was macerated three times with $95 \%$ ethanol $(3 \times 600 \mathrm{ml})$ at room temperature. The aqueous extract was extracted three times with $600 \mathrm{ml}$ of distilled water under reflux for $3 \mathrm{~h}$. The extract solutions were filtered with filter paper (Whatman no. 1) and evaporated under reduced pressure by a rotary evaporator (N-1200B, EYEL A) to obtain aqueous (6.79 g) and ethanolic (4.9 g) extracts. Chromatographic fingerprint profiles obtained by a thin-layer chromatography (TLC) were generated for initial characterization of these extracts. The crude extracts were collected in sterile bottles and kept at $4{ }^{\circ} \mathrm{C}$ until use.

\section{Phytochemical screening}

The extracts of $S$. exigua roots were qualitatively screened to identify the presence of secondary metabolites, including flavonoids, terpenoids, alkaloids, tannins, steroids, cardiac glycosides, saponins, and coumarins [15].

\section{Evaluation of in vitro antioxidant activity}

\section{2,2-Diphenyl-1-picrylhydrazyl (DPPH) radical scavenging} activity assay

The free radical scavenging activity of crude plant extracts was measured by the 2,2-diphenyl-1-picrylhydrazyl (DPPH) assay [16] with some modifications. The plant extracts were diluted with dimethyl sulfoxide (DMSO) (Merck, Germany) to obtain twofold serial dilutions $(1.562-400 \mu \mathrm{g} / \mathrm{ml})$. The reaction mixture, containing 75 $\mu \mathrm{l}$ of plant extract and $150 \mu \mathrm{l}$ of DPPH radical solution (0.1 mM in absolute ethanol), was added into a 96-well plate and incubated in the dark at room temperature for $30 \mathrm{~min}$. L-ascorbic acid $(1.562-100 \mu \mathrm{g} / \mathrm{ml})$ was used as a positive control. The absorbance was measured at $517 \mathrm{~nm}$ by using a microplate reader. The assays were performed in triplicate. The percentage of the radical scavenging activity (\%RSA) was calculated by using the formula below:

$$
\% \text { RSA }=\frac{\text { Abs control }- \text { Abs sample }}{\text { Abs control }} \times 100
$$

where Abs control is the absorbance of DPPH radical + ethanol and Abs sample is the absorbance of DPPH radical + plant extract. 


\section{Superoxide anion scavenging assay}

The superoxide anion scavenging activity was measured as described previously with some modifications [16]. Briefly, the plant extracts were diluted with DMSO to obtain twofold serial dilutions $(1.562-400 \mu \mathrm{g} / \mathrm{ml})$. The reagent mixture, containing $50 \mu \mathrm{l}$ of $0.2 \mathrm{mM}$ nitro blue tetrazolium chloride (NBT) solution (Merck, Germany), $50 \mu \mathrm{l}$ of $25 \mu \mathrm{M}$ phenazine methosulfate (PMS) solution (Merck, Germany), $50 \mu \mathrm{l}$ of $0.5 \mathrm{mM}$ nicotinamide adenine dinucleotide (NADH) solution (Sigma-Aldrich, USA) and $100 \mu \mathrm{l}$ of plant extract, was added into 96-well plates. L-ascorbic acid (Ajax Finechem, USA) was used as a positive control. The plate was incubated at room temperature for $10 \mathrm{~min}$, and the absorbance was measured at $560 \mathrm{~nm}$. The assays were performed in triplicate. The percentage of superoxide radical scavenging activity (SRSA) of the plant extract was calculated by using the formula below, and the results are presented as $\mathrm{IC}_{50}$ values.

$$
\text { \%SRSA }=\frac{\text { Abs control }- \text { Abs sample }}{\text { Abs control }} \times 100
$$

where Abs control is the absorbance without sample and Abs sample is the absorbance with sample.

\section{Hydroxyl radical scavenging assay}

Hydroxyl radical scavenging activity (HRSA) was determined according to the method of Halliwell and Gutteridge [17]. The reaction mixture consisted of $100 \mu \mathrm{l}$ of 50 $\mathrm{mM}$ 2-deoxyribose (Sigma-Aldrich, USA), $100 \mu \mathrm{l}$ of 50 $\mathrm{mM}$ hydrogen peroxide (Merck, Germany), $100 \mu \mathrm{l}$ of 3.2 $\mathrm{mM}$ iron chloride (Sigma-Aldrich, USA), and $100 \mu \mathrm{l}$ of 1 mM disodium EDTA (Sigma-Aldrich, USA), with or without $100 \mu \mathrm{l}$ of plant extract at various concentrations. Butylated hydroxytoluene (BHT) (Sigma-Aldrich, USA) was used as a positive control. The reaction was triggered by adding $100 \mu \mathrm{l}$ of $1.8 \mathrm{mM} \mathrm{L}$-ascorbic acid (Ajax Finechem, USA) and incubated at $37^{\circ} \mathrm{C}$ for $60 \mathrm{~min}$. The reagent mixture, containing $500 \mu \mathrm{l}$ of $10 \%$ trichloroacetic acid (TCA) (Merck, Germany) and $500 \mu \mathrm{l}$ of 5\% 2-thiobarbituric acid (TBA) (Merck, Germany), was added and boiled in a water bath at $95{ }^{\circ} \mathrm{C}$ for $30 \mathrm{~min}$. After cooling at room temperature for $10 \mathrm{~min}$, the absorbance was measured at $532 \mathrm{~nm}$. The assays were performed in triplicate. The percentage of HRSA was calculated by using the following formula, and the results are shown as $\mathrm{IC}_{50}$ values:

$$
\% \text { HRSA }=\frac{\text { Abs control }- \text { Abs sample }}{\text { Abs control }} \times 100
$$

where Abs control is the absorbance without sample and Abs sample is the absorbance with sample.

\section{Experimental animals}

Male ICR mice weighing 24 to $30 \mathrm{~g}$ and aged 4 to 6 weeks were purchased from Nomura Siam International Co., Ltd., Bangkok, Thailand. After the mice arrived at the Animal Research Center, Walailak University, all of them were kept in plastic cages for 7 days before starting the experiment. All experimental animals were housed under standard environmental conditions at a temperature of $22-24{ }^{\circ} \mathrm{C}$ under a $12-\mathrm{h}$ light/dark cycle and had free access to standard pellets and water.

\section{Malaria parasite inoculation}

For thawing of malaria parasites, a frozen vial was placed in a $37{ }^{\circ} \mathrm{C}$ water bath until completely thawed. The malaria parasites were transferred aseptically into a sterile syringe. For inoculation, $200 \mu \mathrm{l}$ of $P$. berghei ANKAinfected red blood cells were injected intraperitoneally into the donor mice. The malaria parasites were obtained through BEI Resources, NIAID, NIH: Plasmodium berghei, Strain ANKA, MRA-311, contributed by Thomas F. McCutchan. When the percentage of parasitemia increased to $5-10 \%$, the donor mice were anesthetized with $60 \mathrm{mg} / \mathrm{kg}$ body weight sodium pentobarbital (Nembutal; Ceva, France), and the blood was collected via cardiac puncture into a heparinized vacutainer tube and used to induce malaria infection in the naive mice for the 4-day suppressive test.

\section{Four-day suppressive test}

The 4-day suppressive test was used to measure the schizonticidal activity of the aqueous and ethanolic extracts against $P$. berghei-infected ICR mice, following a previously described method [18]. Male ICR mice were randomly divided into 9 groups of 5 mice each, including the uninfected group, infected untreated group, artesunate group and six experimental groups with different doses $(200,400$ and $600 \mathrm{mg} / \mathrm{kg})$ of aqueous or ethanolic extract. The mice were injected intraperitoneally with the blood containing $1 \times 10^{7}$ parasitized red blood cells of $P$. berghei ANKA [19]. The six treatment groups were administered aqueous or ethanolic extract of $S$. exigua orally at daily doses of 200,400 and $600 \mathrm{mg} / \mathrm{kg}$. The infected untreated group received $200 \mu \mathrm{l}$ of the solvent used to dissolve the extracts, whereas the positive control group was orally administered $6 \mathrm{mg} / \mathrm{kg}$ body weight artesunate (Sigma-Aldrich, USA) per day. Treatment started $3 \mathrm{~h}$ after the mice had been inoculated with the parasite on day 1 and then continued daily for 4 days (that is, from day 1 to day 5). On day 5, Wright-Giemsastained thin blood smears were prepared from the tail of each animal to detect parasitemia, and percent suppression (\% suppression) was calculated by using the formula below: 


$$
\% \text { Suppression }=\frac{[\mathrm{A}-\mathrm{B}]}{\mathrm{A}} \times 100
$$

where $A$ is the average percentage of parasitemia in the infected untreated group and $B$ is the average percentage of parasitemia in the extract-treated group.

\section{Evaluation of in vivo antioxidant activity Measurement of malondialdehyde}

Malondialdehyde (MDA) was measured by using a commercial kit (cat no. MAK085, Sigma-Aldrich, USA) according to the manufacturer's instructions. Briefly, liver tissue $(50 \mathrm{mg}$ ) was homogenized on ice in $300 \mu \mathrm{l}$ of MDA lysis buffer containing $3 \mu \mathrm{l}$ of BHT $(100 \times)$ and centrifuged at $10,000 \times g$ for $10 \mathrm{~min}$ to remove insoluble material. The supernatant was collected in a microcentrifuge tube. Then, $0.1 \mathrm{M}$ MDA standard solution was prepared by diluting $10 \mu \mathrm{l}$ of $4.17 \mathrm{M}$ MDA standard solution with $407 \mu \mathrm{l}$ of water. To prepare a $2 \mathrm{mM}$ MDA standard, $20 \mu \mathrm{l}$ of the $0.1 \mathrm{M}$ MDA standard solution was diluted with $980 \mu \mathrm{l}$ of water. Then, $0,2,4,6,8$ and $10 \mu \mathrm{l}$ of the $2 \mathrm{mM}$ MDA standard was placed in microcentrifuge tubes. Distilled water was added to each microcentrifuge tube to obtain a final volume of $200 \mu \mathrm{l}$ and to generate 0 (blank), 0.4, 0.8, 1.2, 1.6 and $2.0 \mathrm{nM}$ standards. A total of $600 \mu \mathrm{l}$ of the TBA solution was mixed into each microcentrifuge tube containing sample or standard solution and incubated at $95{ }^{\circ} \mathrm{C}$ for $60 \mathrm{~min}$. After cooling in an ice bath for $10 \mathrm{~min}, 200 \mu \mathrm{l}$ of solution was pipetted from the microcentrifuge tube into a 96-well plate. The assays were performed in triplicate. The absorbance was measured at $532 \mathrm{~nm}$, and the level of MDA was calculated by the following formula:

$$
\mathrm{C}=\left(\mathrm{S}_{\mathrm{a}} / \mathrm{S}_{\mathrm{v}}\right) \times \mathrm{D}
$$

where $C$ is the concentration of MDA in sample, $S_{a}$ is the amount of MDA in unknown sample (nmol) from standard curve, $S_{v}$ is the sample volume $(\mathrm{ml})$ or amount (mg) added into the wells and $D$ is the sample dilution factor (if applicable).

\section{Measurement of superoxide dismutase activity}

Superoxide dismutase (SOD) activity was measured by using a commercial kit based on the WST-8 method (cat no. 19160, Sigma-Aldrich, USA). Briefly, $50 \mathrm{mg}$ of liver tissue was homogenized on ice in cell lysis buffer (Cell Signaling Technology, USA) and centrifuged at 10, $000 \times g$ for $10 \mathrm{~min}$ to remove insoluble material. The supernatant was collected into a microcentrifuge tube. Twenty microliters of sample was added to each sample and the blank 2 well. Twenty microliters of ultrapure $\mathrm{H}_{2} \mathrm{O}$ was added to the blank 1 and blank 3 wells. Two hundred microliters of WST working solution was added to each well, and $20 \mu \mathrm{l}$ of dilution buffer was added to each blank 2 and blank 3 well. Finally, $20 \mu \mathrm{l}$ of enzyme working solution was added to each sample and blank 1 well and incubated at $37{ }^{\circ} \mathrm{C}$ for $20 \mathrm{~min}$. All tests were performed in triplicate. The absorbance was measured at $450 \mathrm{~nm}$ by using a microplate reader. SOD inhibition was calculated by using the following equation:

$$
\begin{array}{r}
\text { SOD inhibition }(\%)=\left(\mathrm{A}_{\text {Blank control 1- }} \mathrm{A}_{\text {Standard or sample }}\right) \\
/\left(\mathrm{A}_{\text {Blank control 1 }}-\mathrm{A}_{\text {Blank control 2 }}\right) \times 100 \%
\end{array}
$$

\section{Acute toxicity test}

The protocol for the acute toxicity test followed the OECD guidelines (2008) [20]. Twenty mice were randomly divided into 4 groups of five mice each. Group I received normal food and water intake without any treatment (untreated group). Group II mice were treated with $200 \mu \mathrm{l}$ of $7 \%$ Tween 80 and 3\% ethanol solution, serving as the negative control group, and groups III and IV were treated with $2000 \mathrm{mg} / \mathrm{kg}$ aqueous and ethanolic extracts, respectively. After treatment, the mice were continuously observed for changes in physical and behavioral activities for $1 \mathrm{~h}$. In addition, the mice were observed daily for 14 days for clinical symptoms and behavioral changes, including central nervous, cardiovascular and gastrointestinal system symptoms, body weight changes, and changes in water and food consumption. On day 14, the mice were anesthetized with $60 \mathrm{mg} / \mathrm{kg}$ sodium pentobarbital (Nembutal; Ceva, France). The blood was harvested via the cardiac puncture technique for liver and kidney function tests. In addition, liver and kidney tissues were collected and preserved in $10 \%$ formaldehyde for histopathological analysis.

\section{Biochemical analysis}

At the end of the acute toxicity test, the blood was centrifuged at $3000 \mathrm{xg}$ for 10 minutes to prepare plasma samples. The plasma samples were transferred to the Medical Technology Clinic, Walailak University, for measurement of liver function (aspartate aminotransferase (AST), alanine aminotransferase (ALT) and alkaline phosphatase (ALP)) and kidney function (blood urea nitrogen (BUN) and creatinine (Cr)) by using an AU480 Chemistry Analyzer (Beckman Coulter, Brea, CA, USA).

\section{Histopathological examination}

The liver and kidney tissues were collected and fixed with $10 \%$ formaldehyde for $24-48 \mathrm{~h}$ and transferred to the Diagnostic Pathology Unit, Department of Tropical Pathology, Mahidol University, for tissue processing and staining. The tissues were dehydrated with an ethanol gradient, incubated in xylene and embedded in paraffin blocks. The paraffin blocks were sectioned at a thickness 
of $5 \mu \mathrm{m}$ using a microtome and stained with hematoxylin and eosin (H\&E). To determine histopathological changes, the stained sections were observed under a light microscope by two independent observers who were blinded to the experimental groups.

\section{Statistical analysis}

Statistical analysis was performed using SPSS for Microsoft Windows, release 17.0 (SPSS, IL, USA). The data was normally distributed assessed by the Shapiro-Wilk test. The differences in parameters among groups were tested using one-way ANOVA, followed by post hoc Tukey's multiple comparison test. The level of statistical significance ( $p$ value) used was less than $0.05(p<0.05)$.

\section{Results}

\section{Phytochemical screening}

The phytochemical screening of the S. exigua root ethanolic extract revealed the presence of high levels of flavonoids, including terpenoids, saponins and coumarins, whereas the $S$. exigua root aqueous extract contained high levels of alkaloids with low levels of flavonoids and terpenoids (Table 1 ).

\section{In vitro antioxidant properties of $S$. exigua root extract}

The antioxidant property was expressed as the $\mathrm{IC}_{50}$ value. The $\mathrm{DPPH}$ radical assay determined the $\mathrm{IC}_{50}$ values of the ethanolic extract, aqueous extract and positive control as $24.63 \pm 1.78,116.32 \pm 4.14$ and $3.99 \pm$ $0.26 \mu \mathrm{g} / \mathrm{ml}$, respectively. The SRSA assay determined the $\mathrm{IC}_{50}$ values of the ethanolic extract, aqueous extract and positive control as $129.78 \pm 0.65,184.62 \pm 3.13$ and $11.77 \pm 0.16 \mu \mathrm{g} / \mathrm{ml}$, respectively (Table 2 ). The HRSA assay determined that the $\mathrm{IC}_{50}$ values of the ethanolic extract, aqueous extract and positive control were 30.58 $\pm 1.19,44.04 \pm 1.37$ and $4.06 \pm 0.95 \mu \mathrm{g} / \mathrm{ml}$, respectively (Table 2). A lower $\mathrm{IC}_{50}$ value indicated a stronger antioxidant effect of the sample. The results from the three methods revealed that the $\mathrm{IC}_{50}$ of the ethanolic extract

Table 1 Phytochemical screening of S. exigua root extract

\begin{tabular}{lll}
\hline $\begin{array}{lll}\text { Phytochemical } \\
\text { constituent }\end{array}$ & \multicolumn{2}{l}{ Type of extract } \\
\cline { 2 - 3 } & Ethanol & Aqueous \\
\hline Flavonoids & +++ & + \\
Terpenoids & + & + \\
Alkaloids & - & +++ \\
Tannins & - & - \\
Steroids & - & - \\
Cardiac glycosides & - & - \\
Saponins & ++ & - \\
Coumarins & + & - \\
\hline
\end{tabular}

+++ represents a strong presence; ++ represents moderate presence; + represents slight presence; - represents absence was lower than the $\mathrm{IC}_{50}$ value of the aqueous extract. Therefore, the in vitro antioxidant study indicated that the ethanolic extract of $S$. exigua roots had stronger antioxidant activity than the aqueous extract.

\section{In vivo antioxidant properties of $S$. exigua root extract Measurement of MDA level}

At the end of the 4-day suppressive test, liver homogenates from mice were used to evaluate the levels of MDA using a lipid peroxidation assay kit. In the present study, malaria-infected mice exhibited a significant increase in MDA levels in liver homogenate compared to the infected untreated group (Table 3). Malaria-infected mice treated with ethanolic extract at doses of 200, 400 and $600 \mathrm{mg} / \mathrm{kg}$ had significantly reduced MDA levels compared to the infected untreated group $(p<0.05)$, whereas aqueous extract at doses of 400 and $600 \mathrm{mg} / \mathrm{kg}$ significantly decreased the MDA level in malariainfected mice compared with that in the infected untreated group $(p<0.05)$. In this study, the antioxidant activity of the ethanolic extract was higher than that of the aqueous extract (Table 3 ).

\section{Measurement of SOD activity}

SOD antioxidant enzyme activity was measured in tissue homogenate by using an SOD activity determination kit, and the results are shown in Table 3 . The mean percentage of SOD inhibition was higher in the tissue homogenate of malaria-infected mice treated with ethanolic and aqueous extracts at doses of 200, 400 and $600 \mathrm{mg} / \mathrm{kg}$ than in the malaria-infected group $(p<0.05)$. In addition, this study found that malaria-infected mice treated with artesunate $(6 \mathrm{mg} / \mathrm{kg}$, as a positive control) exhibited higher inhibition than nontreated malariainfected mice $(p<0.05)$. The malaria-infected mice treated with ethanolic extract showed the highest inhibition, with a value of $67.12 \pm 2.34$ at a dose of $600 \mathrm{mg} /$ $\mathrm{kg}$. In this study, the ethanolic extract also showed higher antioxidant activity than the aqueous extract.

\section{Antimalarial activity of S. exigua root extract}

The percentage of parasite suppression in each group was calculated to determine the antimalarial effect and is summarized in Table 4. This study indicated that ethanolic and aqueous extracts showed dose-dependent chemosuppressive activity against $P$. berghei ANKA. The percent suppression by the ethanolic extract of the plant was $29.60,47.47$ and $53.09 \%$ at doses of 200, 400 and $600 \mathrm{mg} / \mathrm{kg}$, respectively. The percent suppression by the aqueous extract at doses of 200, 400 and $600 \mathrm{mg} / \mathrm{kg}$ was $36.64,52.16$ and $60.46 \%$, respectively. The ethanolic and aqueous extracts showed more effective parasite suppression at the highest dose of $600 \mathrm{mg} / \mathrm{kg}$ than at 200 and $400 \mathrm{mg} / \mathrm{kg}(p<0.05)$. Comparison of the effects of 
Table 2 In vitro antioxidant properties of L-ascorbic acid (a positive control), aqueous and ethanolic extracts of S. exigua roots

\begin{tabular}{llll}
\hline Samples & \multicolumn{1}{l}{$\mathbf{I C}_{\mathbf{5 0}}(\boldsymbol{\mu} \mathbf{g} / \mathbf{m l})$ for radical scavenging } & & Hydroxyl radical \\
\cline { 2 - 4 } & DPPH radical & Superoxide radical & $30.58 \pm 1.19$ \\
\hline Ethanolic extract & $24.63 \pm 1.78$ & $129.78 \pm 0.65$ & $44.04 \pm 1.37$ \\
Aqueous extract & $116.32 \pm 4.14$ & $184.62 \pm 3.13$ & $4.06 \pm 0.95$ \\
L-ascorbic acid & $3.99 \pm 0.26$ & $11.77 \pm 0.16$ & 4 \\
\hline
\end{tabular}

the ethanolic and aqueous S. exigua root extracts at the same dosage revealed that the aqueous extract showed stronger parasite suppression than the ethanolic extract at all dosages $(p<0.05)$.

\section{Acute toxicity test of $S$. exigua root extract} Monitoring general behavioral changes and percentage body weight changes during the acute toxicity test Untreated group and the aqueous extract group exhibited no gross physical and behavioral changes. The ethanolic extract group exhibited decreased locomotor activity and increased self-grooming and hand licking activities. The body weights of the mice were measured at day 0 and day 14 to analyze the percentage of body weight change in each group. The percentage of body weight change was 4.44 in the aqueous extract group and 2.68 in the ethanolic extract group (Table 5). The percentage of body weight change of mice treated with plant extract was significantly lower than that of the untreated group $(p<0.05)$.

\section{Evaluation of the effect of S. exigua root extract on food and water intake}

Water intake and food consumption were measured every day during the acute toxicity test. The water intake and food consumption data were separately analyzed for the first and second weeks and are displayed in Table 6. In the first week, there were no significant differences in water intake and food consumption between the extract-treated groups. In the second week, water intake and food consumption were significantly reduced in mice that received ethanolic extract at a dose of $2000 \mathrm{mg} / \mathrm{kg}$ compared with the untreated group and aqueous extract group $(p<0.05)$.

\section{Biochemical parameters}

Biochemical parameters for liver and kidney functions were analyzed to determine the toxicity of $S$. exigua root extract as shown in Table 7. In the analysis of liver function, the plasma level of AST was significantly elevated in the mice treated with aqueous and ethanolic extracts compared with the untreated group $(p<0.05)$. The plasma level of ALT and ALP was significantly increased in the mice treated with ethanolic extract compared to the untreated group, negative control and aqueous extract group $(p<0.05)$. These findings indicated that ethanolic extract at a dose of $2000 \mathrm{mg} / \mathrm{kg}$ induced liver toxicity. In the kidney function tests, the level of BUN was significantly increased in the mice treated with ethanolic extract compared to the untreated group, negative control group and aqueous extract group $(p<0.05)$. On the other hand, there was no significant difference in creatinine levels among the groups.

\section{Histopathological analysis of the liver and kidneys}

The histological architecture of the liver in the untreated and negative control groups showed normal morphology

Table 3 In vivo antioxidant properties of the aqueous and ethanolic extracts during P. berghei ANKA infection

\begin{tabular}{|c|c|c|}
\hline Group & MDA level (nmol/mg) & SOD inhibition (\%) \\
\hline Uninfected group & $6.55 \pm 1.11^{a}$ & $75.05 \pm 3.53^{a}$ \\
\hline Infected untreated group & $18.38 \pm 1.34$ & $57.89 \pm 1.05$ \\
\hline Artesunate 6 mg/kg & $7.42 \pm 1.61^{\mathrm{a}}$ & $73.07 \pm 0.02^{a}$ \\
\hline Ethanolic extract 200 mg/kg & $8.58 \pm 0.90^{a}$ & $61.60 \pm 3.92$ \\
\hline Ethanolic extract 400 mg/kg & $8.41 \pm 0.70^{a}$ & $64.82 \pm 3.00^{a}$ \\
\hline Ethanolic extract 600 mg/kg & $7.36 \pm 0.84^{a}$ & $67.12 \pm 2.34^{a}$ \\
\hline Aqueous extract 200 mg/kg & $16.65 \pm 1.86$ & $59.86 \pm 0.61$ \\
\hline Aqueous extract 400 mg/kg & $10.27 \pm 0.67^{a}$ & $63.79 \pm 1.74^{a}$ \\
\hline Aqueous extract 600 mg/kg & $8.95 \pm 0.75^{a}$ & $64.82 \pm 3.00^{a}$ \\
\hline
\end{tabular}

Data are presented as the mean \pm SD ( $n=5$ per group)

Data were analyzed by one-way ANOVA, followed by post hoc Tukey's multiple comparison test

${ }^{a} p<0.05$, significantly different compared to the infected untreated group 
Table 4 Antimalarial activity of artesunate (a positive control), aqueous and ethanolic extracts

\begin{tabular}{lll}
\hline Group & \% Parasitemia & \% Suppression \\
\hline Infected untreated group & $6.57 \pm 1.89$ & - \\
Artesunate $6 \mathrm{mg} / \mathrm{kg}$ & $0.18 \pm 0.56$ & $97.15 \pm 0.92$ \\
Ethanolic extract $200 \mathrm{mg} / \mathrm{kg}$ & $5.17 \pm 0.89$ & $29.60 \pm 3.96^{\mathrm{a}, \mathrm{b}}$ \\
Ethanolic extract $400 \mathrm{mg} / \mathrm{kg}$ & $4.62 \pm 0.34$ & $47.47 \pm 0.38^{\mathrm{a}, \mathrm{c}}$ \\
Ethanolic extract $600 \mathrm{mg} / \mathrm{kg}$ & $3.45 \pm 0.03$ & $53.09 \pm 0.64^{\mathrm{c}}$ \\
Aqueous extract $200 \mathrm{mg} / \mathrm{kg}$ & $4.16 \pm 0.33$ & $36.64 \pm 4.21^{\mathrm{c}}$ \\
Aqueous extract $400 \mathrm{mg} / \mathrm{kg}$ & $3.14 \pm 0.35$ & $52.16 \pm 3.77^{\mathrm{c}}$ \\
Aqueous extract $600 \mathrm{mg} / \mathrm{kg}$ & $2.59 \pm 0.03$ & $60.46 \pm 0.38$
\end{tabular}

Data are presented as the mean \pm SD ( $n=5$ per group)

Data were analyzed by one-way ANOVA, followed by post hoc Tukey's multiple comparison test

${ }^{a} p<0.05$, significantly different compared to $600 \mathrm{mg} / \mathrm{kg}$ ethanolic extract ${ }^{b} p<0.05$, significantly different compared to $200 \mathrm{mg} / \mathrm{kg}$ aqueous extract

${ }^{c} p<0.05$, significantly different compared to $600 \mathrm{mg} / \mathrm{kg}$ aqueous extract

of hepatocytes with an acidophilic cytoplasm and normal structure of hepatic sinusoids and the central vein (Fig. 1). The hepatological analysis of mice treated with aqueous extract at a single dose of $2000 \mathrm{mg} / \mathrm{kg}$ showed mild hepatocyte necrosis and infiltration of inflammatory cells. Mice treated with ethanolic extract at a single dose of $2000 \mathrm{mg} / \mathrm{kg}$ showed ballooning degeneration of hepatocytes, diffuse hepatic hemorrhage and infiltration of inflammatory cells. The histopathological assessment of the kidney in all groups showed no change in the histological architecture of glomerular and renal tubules compared to the untreated group.

\section{Discussion}

In this study, the antioxidant properties of aqueous and ethanolic $S$. exigua root extracts were determined by the DPPH radical assay and SRSA and HRSA assays. The three antioxidant assays are commonly used for screening the in vitro antioxidant properties of plant extracts $[21,22]$. Our study showed that the ethanolic extract of $S$. exigua root exhibited inhibition of DPPH radicals, superoxide anions and hydroxyl radicals, with $\mathrm{IC}_{50}$

Table 5 Evaluation of percent body weight change in the untreated, aqueous and ethanolic extract groups during acute toxicity experiments

\begin{tabular}{llll}
\hline Groups & \multicolumn{2}{l}{ Mean body weight $(\mathbf{g})$} & \multirow{2}{*}{$\%$ Change } \\
\cline { 2 - 3 } & Day 0 & Day 14 & \\
\hline Untreated group & $31.63 \pm 0.30$ & $35.39 \pm 0.83$ & $11.88 \pm 3.71$ \\
Aqueous extract $2000 \mathrm{mg} / \mathrm{kg}$ & $26.59 \pm 0.99$ & $27.76 \pm 0.86$ & $4.44 \pm 1.59^{\mathrm{a}}$ \\
Ethanol extract $2000 \mathrm{mg} / \mathrm{kg}$ & $27.26 \pm 1.60$ & $27.98 \pm 1.33$ & $2.68 \pm 2.21^{\mathrm{a}}$ \\
\hline $\begin{array}{l}\text { Data are presented as the mean } \pm \text { SD ( } n=5 \text { per group }) \\
\text { Data were analyzed by one-way ANOVA, followed by post hoc Tukey's } \\
\text { multiple comparison test } \\
{ }^{a} p<0.05, \text { significantly different compared to the untreated group }\end{array}$
\end{tabular}

Table 6 Daily monitoring of food and water consumption in the untreated, aqueous and ethanolic extract groups during acute toxicity experiments

\begin{tabular}{|c|c|c|c|}
\hline \multirow[t]{2}{*}{ Parameter } & \multicolumn{2}{|l|}{ Group } & \multirow{2}{*}{$\begin{array}{l}\text { Ethanolic } \\
\text { extract }\end{array}$} \\
\hline & Untreated & Aqueous extract & \\
\hline \multicolumn{4}{|c|}{ Food consumption (g/week) } \\
\hline Week 1: Days 1-7 & $27.85 \pm 3.93$ & $26.42 \pm 6.26$ & $26.85 \pm 3.76$ \\
\hline Week 2: Days 8-14 & $23.57 \pm 4.75$ & $26.14 \pm 7.35$ & $19.28 \pm 3.45^{\mathrm{a}, \mathrm{b}}$ \\
\hline \multicolumn{4}{|c|}{ Water consumption (ml/week) } \\
\hline Week 1: Days 1-7 & $25.71 \pm 7.31$ & $27.42 \pm 3.73$ & $22.85 \pm 5.66$ \\
\hline Week 2: Days 8-14 & $23.57 \pm 3.77$ & $20.71 \pm 3.45$ & $17.21 \pm 3.78^{\mathrm{a}, \mathrm{b}}$ \\
\hline
\end{tabular}

Data are the mean \pm SD ( $n=5$ per group)

Data were analyzed by one-way ANOVA, followed by post hoc Tukey's multiple comparison test

${ }^{a} p<0.05$, significantly different compared to the untreated group

${ }^{\mathrm{b}} p<0.05$, significantly different compared to the aqueous extract group

values of $24.63 \pm 1.78,129.78 \pm 0.65$ and $30.58 \pm 1.19$ $\mu \mathrm{g} / \mathrm{ml}$, respectively. A DPPH radical assay of plant ingredients in Kheaw-hom remedy showed that the ethanolic extract of $S$. exigua root strongly inhibited DPPH radicals with an $\mathrm{IC}_{50}$ value of $9.42 \pm 2.11 \mu \mathrm{g} / \mathrm{ml}$ [12], which was similar to the result of this study. The results from phytochemical screening of the $S$. exigua root extract showed that the ethanolic extract contained flavonoids, including terpenoids, saponins and coumarins, whereas the aqueous extract contained alkaloids, flavonoids and terpenoids. These results are consistent with a previous report showing that the Sophora genus contains four main groups, namely, alkaloids, flavonoids, polysaccharides and fatty acids [11]. A previous study reported that plant crude extracts containing flavonoids and polyphenol compounds act as reducing agents and antioxidants [23]. These compounds contain hydroxyl groups and mediate their antioxidant effects by scavenging free radicals [24]. They act as hydrogen-donating antioxidants and can react with lipid peroxyl radicals, resulting in breakage of the generation cycle of new radicals [25].

To evaluate the in vivo antioxidant properties of $S$. exigua root extract, we demonstrated that malaria-infected mice treated with ethanolic extract at doses of 200, 400 and $600 \mathrm{mg} / \mathrm{kg}$ had significantly reduced MDA levels compared to the infected untreated group. The mean rate of SOD inhibition was higher in the tissue homogenate of malaria-infected mice treated with ethanolic and aqueous extracts at doses of 200, 400 and $600 \mathrm{mg} /$ $\mathrm{kg}$ than in tissue homogenates from the infected untreated group. The MDA level and SOD activity are commonly used as measures of oxidative stress in cardiovascular disease [26] and malaria infection [27]. During plasmodium parasite infection, increased MDA levels and decreased SOD activity were found in human and murine models [28, 29]. Sophoraflavanone G extracted from $S$. exigua roots exerts antimicrobial activity 
Table 7 Liver and kidney biochemical analyses of the untreated, negative control and aqueous and ethanolic extract groups during acute toxicity experiments

\begin{tabular}{|c|c|c|c|c|}
\hline Parameter & Untreated & Negative & Aqueous extract & Ethanolic extract \\
\hline \multicolumn{5}{|l|}{ Liver function tests } \\
\hline AST (U/L) & $143.50 \pm 6.36$ & $164.66 \pm 3.33^{a}$ & $161.70 \pm 8.30^{a}$ & $238.50 \pm 2.50^{\mathrm{a}}$ \\
\hline $\operatorname{ALT}(\mathrm{U} / \mathrm{L})$ & $33.25 \pm 4.45$ & $28.44 \pm 2.98$ & $27.70 \pm 3.70$ & $42.00 \pm 4.35^{a, b, c}$ \\
\hline ALP (U/L) & $84.50 \pm 0.70$ & $86.00 \pm 3.05$ & $80.55 \pm 8.45$ & $111.00 \pm 7.02^{\mathrm{a}, \mathrm{b}, \mathrm{c}}$ \\
\hline \multicolumn{5}{|l|}{ Kidney function tests } \\
\hline BUN (mg/dL) & $23.55 \pm 0.21$ & $24.00 \pm 2.00$ & $26.33 \pm 2.08$ & $31.00 \pm 0.30^{a, b, c}$ \\
\hline Creatinine $(\mathrm{mg} / \mathrm{dL})$ & $0.55 \pm 0.06$ & $0.56 \pm 0.02$ & $0.55 \pm 0.01$ & $0.54 \pm 0.02$ \\
\hline
\end{tabular}

Data are the mean \pm SD $(n=5$ per group)

${ }^{a} p<0.05$, significantly different compared to the untreated group

${ }^{\mathrm{b}} p<0.05$, significantly different compared to the negative control group

${ }^{c} p<0.05$, significantly different compared to the aqueous extract group

by decreasing the fluidity of cellular membranes [14]. Additionally, it has been reported that sophoraflavanone treatment led to increased SOD activity and decreased MDA levels in the serum of diabetic rats with streptozotocin (STZ)-induced inflammation [30].

According to the 4-day suppressive test, the crude extracts were found to decrease the level of parasitemia in a dose-dependent manner. This study demonstrated that the aqueous extract of $S$. exigua root exhibited stronger antimalarial activity than the ethanolic extract. The aqueous extract at a dose of $600 \mathrm{mg} / \mathrm{kg}$ suppressed parasitemia with a suppression value of $60.46 \%$. According to the results of this study, this effect may be attributed mainly to the alkaloid, flavonoid and terpenoid compounds that were the secondary metabolites present in the aqueous extract. Regarding alkaloids, several classes of these compounds, including indole, bisindole, quinolone and isoquinoline alkaloids isolated from different medicinal plants, were identified as having promising antimalarial activity [31]. A previous study reported that some sesquiterpenoid and triterpenoid compounds inhibit parasite growth by inhibiting the polymerization of heme to hemozoin through free radical formation of sesquiterpenic lactone. Furthermore, these compounds were reported to inhibit protein synthesis in parasitic cells and inhibit PfATP6, a $\mathrm{Ca}^{2+}$ ion transporter that is a sarcoendoplasmic reticulum calcium-dependent ATPase (SERCA) [32]. Additionally, monoterpenoid indole alkaloids such as uleine also inhibit heme polymerization as a result of the presence of a basic aliphatic amino group that undergoes protonation in the acidic digestive vacuole [33]. For flavonoids, it is believed that this compound acts by inhibiting fatty acid biosynthesis (FAS II) in the parasite. In addition, some flavonoids have also been reported to inhibit the growth of malaria parasites by inhibiting the influx of L-glutamine and myoinositol into infected erythrocytes [34]. Therefore, antimalarial effect of aqueous extract of $S$. exigua root against $P$. berghei ANKA might be attributed to a single or a combination of its secondary metabolites, leading to alteration of protein structure and impairment of its function and inhibition of blood stage propagation of parasites [35].

A previous study showed that an isolated S. exigua root extract contained exiguaflavanone A, exiguaflavanone B and sophoraflavanone G [36]. It has been reported that the flavanone compounds exiguaflavanones A and B isolated from Artemisia indica Willd exhibited in vitro antimalarial activity against $P$. falciparum with $\mathrm{IC}_{50}$ values of 4.60 and $7.05 \mu \mathrm{g} / \mathrm{ml}$, respectively [37]. Antimalarial testing of (2S)-2'-methoxykurarinone, sophoraflavanone $\mathrm{G}$ and leachianone A isolated from the roots of $S$. flavescens demonstrated moderate antimalarial activity, with $\mathrm{IC}_{50}$ values of $2.4,2.6$ and $2.1 \mu \mathrm{M}$, respectively [10]. The effect of S. exigua on antimalarial activity may be due to exiguaflavanones $A$ and $B$ as well as sophoraflavanone G, which might be the active compounds in this plant. Therefore, our study suggests that further investigation is required to characterize the active compounds of the aqueous extract of $S$. exigua roots that have potent effects on the inhibition of malaria parasites.

Regarding acute oral toxicity, the ethanolic and aqueous extracts did not cause any obvious mortality in the experimental mice at $2000 \mathrm{mg} / \mathrm{kg}$ oral administration. This revealed that a lethal dose of $50 \%$ is greater than $2000 \mathrm{mg} / \mathrm{kg}$. In the present study, the mice were observed daily for 14 days to determine body weight changes, and changes in water and food consumption. The percentage of body weight change was very less in those mice treated with both crude extracts as compared with mice in untreated group. The water intake and food consumption in mice that received ethanolic extract were significantly reduced. Therefore, ethanolic extract might be affect increasing body weight through appetite suppression.

In this study, the plasma levels of AST, ALT, ALP and BUN were increased in the mice treated with $2000 \mathrm{mg} / \mathrm{kg}$ ethanolic extract compared to the untreated group. This 


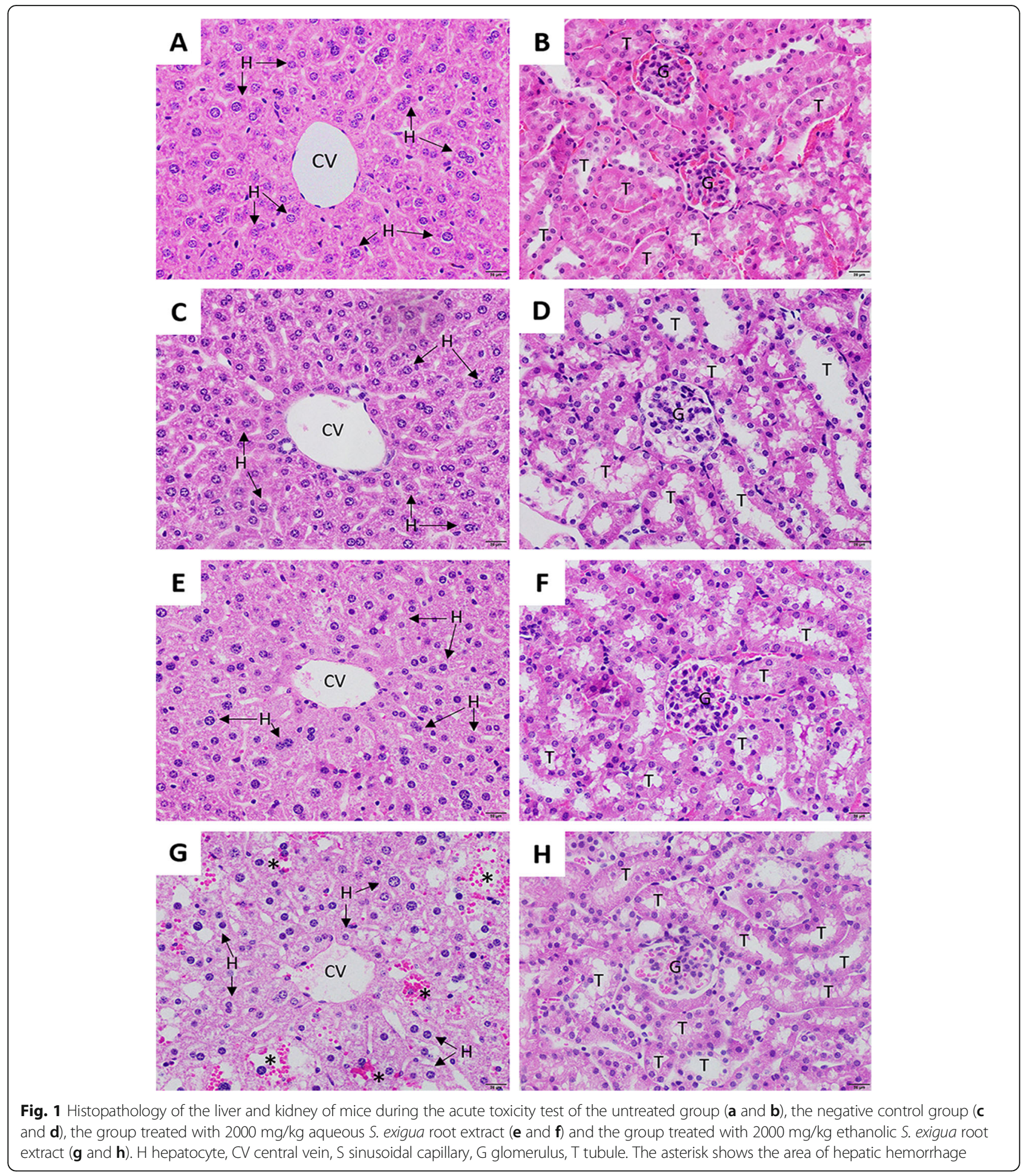

finding was related to the results obtained from histopathological analysis of liver tissue. The histopathological analysis revealed that mice treated with ethanolic extract at a single dose of $2000 \mathrm{mg} / \mathrm{kg}$ showed ballooning degeneration of hepatocytes, diffuse hepatic hemorrhage, and infiltration of inflammatory cells. The liver is a primary organ involved in the biotransformation of food and drugs after oral administration. The cause of hepatic injury is toxic chemicals; xenobiotics; anticancer, immunosuppressant, analgesic, anti-inflammatory, and antitubercular drugs; and biological agents that show the ability to induce hepatic injury [38]. Previous studies have demonstrated 
that sophoraflavanone G isolated from S. exigua root and $S$. flavescens has cytotoxic effects on human myeloid leukemia HL60 cells $[39,40]$. In addition, it has been reported that sophoraflavanone $\mathrm{G}$ has potent toxic effects on primary rat hepatocytes and human HL-7702 liver cells, with $\mathrm{IC}_{50}$ values of 16.5 and $40.3 \mu \mathrm{M}$, respectively [41]. A previous study showed that sophoraflavanone G inhibited cytochrome P450 activity by inhibiting CYP2B6 and CYP3A4 [42]. Therefore, the ethanolic extract of $S$. exigua roots is required for further investigation to confirm its safety at lower doses.

\section{Conclusions}

This study demonstrated that the ethanolic S. exigua root extract possesses antioxidant properties and that the aqueous extract also has antimalarial activity. Additionally, hepatotoxic effects of the $S$. exigua root ethanolic extract were observed at $2000 \mathrm{mg} / \mathrm{kg}$ body weight. The appropriate dose of $S$. exigua root extract for antimalarial activity needs to be further investigated.

\section{Acknowledgements}

We are sincerely grateful to all the technical staff at the Animal Experiment Building, Walailak University, for their help with performing the animal experiment. We thank all of the staff at the Department of Tropical Pathology, Faculty of Tropical Medicine, Mahidol University, Thailand, for their assistance with histological processing.

\section{Authors' contributions}

KK, PC, PJ, AP and CP conceived and designed the study. KK and AP performed the laboratory work. KK, PC and CP analyzed the data. KK, PC, PJ, $A P$ and $C P$ were involved in the drafting of the manuscript. $P C$ and $C P$ were involved in the critical review of the manuscript. The authors read and approved the final manuscript.

\section{Funding}

This research received no funding support.

\section{Availability of data and materials}

All data generated or analyzed during this study are available from the corresponding author on reasonable request.

\section{Declarations}

\section{Ethics approval and consent to participate}

The animal protocol was reviewed and approved by the Animal Ethics Committee, Walailak University (clearance no. WU-AICUC-026-62).

\section{Consent for publication}

Not applicable.

\section{Competing interests}

The authors have no conflicts of interest related to this study.

Received: 2 November 2020 Accepted: 9 March 2021

Published online: 19 March 2021

\section{References}

1. Talapko J, Skrlec I, Alebic T, Jukic M, Vcev A. Malaria: the past and the present. Microorganisms. 2019;7(6):179.

2. WHO. World malaria report. Geneva: WHO; 2018

3. Percário S, Moreira DR, Gomes BAQ, Ferreira MES, Gonçalves ACM, Laurindo PSOC, et al. Oxidative stress in malaria. Int J Mol Sci. 2012;13(12):16346-72.

4. Postma NS, Zuidema J, Mommérs EC, Eling WMC. Oxidative stress in malaria; implications for prevention and therapy. Pharm World Sci. 1996;18(4):121-9.
5. Maneerat $Y$, Viriyavejakul $P$, Punpoowong $B$, Jones $M$, Wilairatana $P$, Pongponratn $\mathrm{E}$, et al. Inducible nitric oxide synthase expression is increased in the brain in fatal cerebral malaria. Histopathology. 2000;37(3):269-77.

6. Nanda R, Mishra PK, Das UK, Rout SB, Mohapatra PC, Panda A. Evaluating role of oxidative stress in determining the pathogenesis of falciparum malaria induced acute renal failure. Indian J Clin Biochem. 2004;19(1):93-6.

7. Guha M, Kumar S, Choubey V, Maity P, Bandyopadhyay U. Apoptosis in liver during malaria: role of oxidative stress and implication of mitochondrial pathway. FASEB J. 2006;20(8):1224-6.

8. Jung HA, Jeong DM, Chung HY, Lim HA, Kim JY, Yoon NY, et al. Reevaluation of the antioxidant prenylated flavonoids from the roots of Sophora flavescens. Biol Pharm Bull. 2008;31(5):908-15.

9. Tang YP, Li YF, Hu J, Lou FC. Isolation and identification of antioxidants from Sophora japonica. J Asian Nat Prod Res. 2002;4(2):123-8.

10. Kim YC, Kim HS, Wataya Y, Sohn DH, Kang TH, Kim MS, et al. Antimalarial activity of lavandulyl flavanones isolated from the roots of Sophora flavescens. Biol Pharm Bull. 2004:27(5):748-50.

11. Krishna PM, KNV Rao, Sandhya SI, Banji D. A review on phytochemical, ethnomedical and pharmacological studies on genus Sophora, Fabaceae. Rev Bras Farmacogn. 2012;22:1145-54.

12. Ouncharoen $\mathrm{K}$, Itharat $\mathrm{A}$, Chaiyawatthanananthn $\mathrm{P}$. In vitro free radical scavenging and cell-based antioxidant activities of Kheaw-Hom remedy extracts and its plant ingredients. J Med Assoc Thai. 2017;100(204):241.

13. Sohn HY, Son KH, Kwon CS, Kwon GS, Kang SS. Antimicrobial and cytotoxic activity of 18 prenylated flavonoids isolated from medicinal plants: Morus alba L., Morus mongolica Schneider, Broussnetia papyrifera (L.) Vent, Sophora flavescens Ait and Echinosophora koreensis Nakai. Phytomedicine. 2004;11(7): $666-72$

14. Tsuchiya $H$, linuma M. Reduction of membrane fluidity by antibacterial sophoraflavanone G isolated from Sophora exigua. Phytomedicine. 2000;7(2): $161-5$.

15. Majouli K, Hamdi A, Hlila MB. Phytochemical analysis and biological activities of Hertia cheirifolia L. roots extracts. Asian Pac J Trop Med. 2017; 10(12):1134-9.

16. Jing L, Ma H, Fan P, Gao R, Jia Z. Antioxidant potential, total phenolic and total flavonoid contents of Rhododendron anthopogonoides and its protective effect on hypoxia-induced injury in PC12 cells. BMC Complement Altern Med. 2015;15:287.

17. Halliwell B, Gutteridge JM. Formation of thiobarbituric-acid-reactive substance from deoxyribose in the presence of iron salts: the role of superoxide and hydroxyl radicals. FEBS Lett. 1981;128(2):347-52.

18. Peters $W$. The chemotherapy of rodent malaria, XXII. The value of drugresistant strains of $P$. berghei in screening for blood schizontocidal activity. Ann Trop Med Parasitol. 1975;69(2):155-71.

19. Dambuza NS, Smith P, Evans A, Norman J, Taylor D, Andayi A, et al. Antiplasmodial activity, in vivo pharmacokinetics and anti-malarial efficacy evaluation of hydroxypyridinone hybrids in a mouse model. Malar J. 2015; 14(1):505

20. OECD. Test No. 425: Acute oral toxicity: up-and-down procedure, OECD guidelines for the testing of chemicals, section 4. Paris; 2008.

21. Zou Y, Zhao Y. Hu W. Chemical composition and radical scavenging activity of melanin from Auricularia auricula fruiting bodies. Food Sci Technol. 2015; 35:253-8.

22. Lalhminghlui K, Jagetia GC. Evaluation of the free-radical scavenging and antioxidant activities of Chilauni, Schima wallichii Korth in vitro. Future Sci OA. 2018;4(2):FSO272-FSO

23. Kefayati Z, Motamed SM, Shojaii A, Noori M, Ghods R. Antioxidant activity and phenolic and flavonoid contents of the extract and subfractions of Euphorbia splendida Mobayen. Pharmacognosy Res. 2017:9(4):362-5.

24. Kumar S, Pandey AK. Chemistry and biological activities of flavonoids: An overview. Sci World J. 2013;2013:162750.

25. Riaz T, Abbasi M, Shahzadi T, Ajaib M, Khan K. Phytochemical screening, free radical scavenging, antioxidant activity and phenolic content of Dodonaea viscosa Jacq. J Serb Chem Soc. 2012;77(4):423-35.

26. Ho E, Karimi Galougahi K, Liu C-C, Bhindi R, Figtree GA. Biological markers of oxidative stress: applications to cardiovascular research and practice. Redox Biol. 2013;1(1):483-91.

27. Pabon A, Carmona J, Burgos LC, Blair S. Oxidative stress in patients with non-complicated malaria. Clin Biochem. 2003;36(1):71-8.

28. Narsaria N, Mohanty C, Das BK, Mishra SP, Prasad R. Oxidative stress in children with severe malaria. J Trop Pediatr. 2011;58(2):147-50. 
29. Mubaraki MA, Hafiz TA, Al-Quraishy S, Dkhil MA. Oxidative stress and genes regulation of cerebral malaria upon Zizyphus spina-christi treatment in a murine model. Microb Pathog. 2017;107:69-74.

30. Wang $H$, Chen $L$, Zhang L, Gao X, Wang Y, Weiwei T. Protective effect of sophoraflavanone $\mathrm{G}$ on streptozotocin (STZ)-induced inflammation in diabetic rats. Biomed Pharmacother. 2016;84:1617-22.

31. Uzor PF. Alkaloids from plants with antimalarial activity: a review of recent studies. Evid Based Complement Alternat Med. 2020;2020:8749083.

32. Alkandahri MY, Berbudi A, Vicahyani Utami N, Subarnas A. Antimalarial activity of extract and fractions of Castanopsis costata (Blume) A.DC. Avicenna J Phytomed. 2019;9(5):474-81.

33. Tajuddeen N, Van Heerden FR. Antiplasmodial natural products: an update Malar J. 2019;18(1):404

34. Ntie-Kang F, Onguene PA, Lifongo LL, Ndom JC, Sippl W, Mbaze LM. The potential of anti-malarial compounds derived from African medicinal plants, part II: a pharmacological evaluation of non-alkaloids and non-terpenoids. Malar J. 2014;13:81.

35. Fenta M, Kahaliw W. Evaluation of antimalarial activity of hydromethanolic crude extract and solvent fractions of the leaves of Nuxia congesta R. Br. Ex Fresen (Buddlejaceae) in Plasmodium berghei infected mice. J Exp Pharmacol. 2019;11:121-34

36. Ruangrungsi N, linuma M, Tanaka T, Ohyama M, Yokoyama J, Mizuno M. Three flavanones with a lavandulyl group in the roots of Sophora exigua. Phytochemistry. 1992;31(3):999-1001.

37. Chanphen R, Thebtaranonth Y, Wanauppathamkul S, Yuthavong Y. Antimalarial principles from Artemisia indica. J Nat Prod. 1998;61(9):1146-7.

38. Contreras-Zentella ML, Hernández-Muñoz R. Is liver enzyme release really associated with cell necrosis induced by oxidant stress? Oxidative Med Cell Longev. 2016;2016:3529149.

39. Kang T-H, Jeong S-J, Ko W-G, Kim N-Y, Lee B-H, Inagaki M, et al. Cytotoxic lavandulyl flavanones from Sophora flavescens. J Nat Prod. 2000;63(5):680-1.

40. Li Z-Y, Huang W-C, Tu R-S, Gu P-Y, Lin C-F, Liou C-J. Sophoraflavanone G induces apoptosis in human leukemia cells and blocks MAPK activation. Am J Chin Med. 2016;44(01):165-76.

41. Yu Q, Cheng N, Ni X. Identifying 2 prenylflavanones as potential hepatotoxic compounds in the ethanol extract of Sophora flavescens. J Food Sci. 2013; 78(11):T1830-T4.

42. Yim D, Kim MJ, Shin Y, Lee S-J, Shin JG, Kim DH. Inhibition of cytochrome P450 activities by Sophora flavescens extract and its prenylated flavonoids in human liver microsomes. Evid Based Complement Alternat Med. 2019;2019: 2673769.

\section{Publisher's Note}

Springer Nature remains neutral with regard to jurisdictional claims in published maps and institutional affiliations.

Ready to submit your research? Choose BMC and benefit from:

- fast, convenient online submission

- thorough peer review by experienced researchers in your field

- rapid publication on acceptance

- support for research data, including large and complex data types

- gold Open Access which fosters wider collaboration and increased citations

- maximum visibility for your research: over $100 \mathrm{M}$ website views per year

At BMC, research is always in progress.

Learn more biomedcentral.com/submissions 